\title{
Contaminação ambiental e perfil toxigênico de Bacillus cereus isolados em serviços de alimentação
}

\author{
Environmental contamination and enterotoxigenic profile of Bacillus cereus isolated in food services
}

\author{
Celina Mara Soares $^{{ }^{*}}$ Geórgio Freesz Valadares $^{\mathrm{II}}$ Raquel Monteiro Cordeiro de Azeredo ${ }^{\mathrm{III}}$ \\ Arnaldo Yoshiteru Kuaye ${ }^{\mathrm{IV}}$
}

\section{RESUMO}

A avaliação da contaminação ambiental por Bacillus cereus foi realizada em 90 amostras de ar ambiente e em 96 amostras de superfícies de bancadas e de equipamentos, de dois restaurantes institucionais. O microrganismo foi detectado em $84,4 \%$ e $44,8 \%$ das amostras de ar ambiente $e$ de superfícies, respectivamente. O potencial enterotoxigênico dos isolados foi investigado através da reação da polimerase em cadeia (PCR) para os genes hblA, hblD e hblC (que codificam a hemolisina $B L$ ) e para os genes nheA, nheB $e$ nheC (que codificam a enterotoxina não hemolítica - NHE). De um total de 70 isolados investigados, $14,3 \%$ foram positivos para os três genes da HBL e 12,8\% foram positivos para os três genes da NHE. A produção de NHE também foi verificada através do Bacillus Diarrhoeal Enterotoxin Visual Immunoassay (kit BDE-VIA; Tecra). Os resultados obtidos com o kit revelaram que $61,4 \%$ dos 70 isolados são produtores de NHE.

Palavras-chave: segurança alimentar, hemolisina, enterotoxina diarréica, PCR, ELISA.

\section{ABSTRACT}

Ninety air samples and ninety six samples from benches and equipments surfaces were collected in two food services for investigation of Bacillus cereus contamination sources and characterization of strains toxin profiles. B. cereus was detected in $84.4 \%$ and $44.8 \%$ from air samples and samples from benches and equipments surfaces, respectively. The potential of enterotoxin production was investigated using polymerase chain reaction (PCR) methods for genes hblA, hblD e hblC (encoding hemolysin $B L$ ) and for genes nhe $A$, nheB and nheC (encoding non-hemolytic enterotoxin - NHE). From 70 isolates investigated $14.3 \%$ were positive for the three $H B L$ encoding genes and $12.8 \%$ were positive for the three
NHE encoding genes. The Bacillus Diarrhoeal Enterotoxin Visual Immunoassay (BDE-VIA; Tecra) also was used for NHE detection. The results obtained with $B D E-V I A$ revealed that $61.4 \%$ from the 70 strains are NHE producers.

Key words: safe food, hemolysin, diarrhoeal enterotoxin, PCR, ELISA.

\section{INTRODUÇÃO}

Bacillus cereus é um microrganismo Gram positivo amplamente distribuído na natureza, sendo o solo seu reservatório natural. A presença da bactéria ou de seus esporos em alimentos é relativamente freqüente. Devido a algumas propriedades dos esporos - como a sobrevivência em diferentes temperaturas e valores de $\mathrm{pH}$, resistência à desidratação e irradiação e capacidade de adesão às superfícies que contatam alimentos - a indústria de alimentos encontra dificuldades para eliminar o microrganismo do ambiente industrial (ANDERSSON et al., 1995; KOTIRANTA et al., 2000). B. cereus é isolado a partir de produtos crus e processados, como arroz, condimentos, vegetais, preparações cárneas e laticínios. Esse microrganismo está associado a duas doenças transmitidas por alimentos, denominadas de "síndrome emética" e “síndrome diarréica” (KRAMER \& GILBERT, 1989).

A síndrome diarréica é caracterizada por dor abdominal, diarréia e náuseas que se estendem por 12

\footnotetext{
'Programa de Pós-graduação, Faculdade de Engenharia de Alimentos (FEA), Universidade Estadual de Campinas (UNICAMP). Campinas, SP, Brasil. E-mail: celinamsoares@yahoo.com.br. *Autor para correspondência.

"Programa de Pós-graduação, Instituto de Biologia, UNICAMP. Campinas. SP. Brasil.

II'Departamento de Nutrição e Saúde, Universidade Federal de Viçosa (UFV). Viçosa, MG, Brasil.

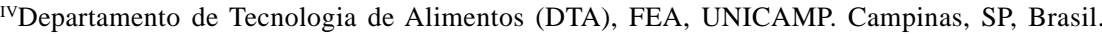


a 24h (GRANUM, 1994). Essa doença está associada a várias enterotoxinas, dentre elas, a enterotoxina hemolisina BL (HBL) e a enterotoxina não-hemolítica (NHE). Essas enterotoxinas foram estudadas e caracterizadas por alguns pesquisadores (BEECHER \& MACMILLAN, 1991; HEINRICHS et al., 1993; LUND \& GRANUM, 1996; RYAN et al., 1997; GRANUM et al., 1999). O complexo HBL é formado por três componentes denominados $\mathrm{B}, \mathrm{L}_{1}$ e $\mathrm{L}_{2}$ (pesos moleculares de 35, 36 e $45 \mathrm{kDa}$, respectivamente) (BEECHER \& MACMILLAN, 1991) e requer os três componentes para intensificar ao máximo as atividades hemolítica, citotóxica e dermonecrótica, além da ação de permeabilidade vascular e de acúmulo de fluido em alças intestinais de coelho (BEECHER et al., 1995). O gene do componente B da HBL, denominado de $h b l A$, foi seqüenciado por HEINRICHS et al. (1993). Os genes responsáveis pelas frações $L_{1}$ e $L_{2}$, foram seqüenciados por RYAN et al. (1997) e denominados respectivamente por hblD e hblC. O complexo NHE é composto por três proteínas de peso molecular igual a 39, 45 e 105kDa e também requer todos os componentes para a sua máxima toxicidade em testes com células Vero (african green monkey kidney) e Caco-2 (human intestinal epithelial cells) (LUND \& GRANUM, 1996). Os genes que codificam as três proteínas que compõem a NHE foram seqüenciados por GRANUM et al. (1999) e denominados nheA, nheB e nheC.

No presente estudo, avaliou-se a contaminação ambiental por $\boldsymbol{B}$. cereus em serviços de alimentação através de análises microbiológicas. O perfil toxigênico dos isolados foi investigado utilizando-se as técnicas de ELISA e da reação da polimerase em cadeia (PCR), considerando-se os complexos HBL e NHE. A pesquisa foi realizada em dois restaurantes institucionais, através da análise de amostras do ar ambiente e de superfícies de bancadas e equipamentos.

\section{MATERIAL E MÉTODOS}

Amostras ambientais

As amostras ambientais foram coletadas em dois restaurantes institucionais: restaurante 1 (R1), que prepara cerca de 6 mil refeições diárias, e restaurante 2 (R2), onde são preparadas cerca de 2 mil refeições diárias. A coleta das amostras foi realizada conforme metodologia descrita por EVANCHO et al. (2001).

Amostras de ar ambiente (500 l) foram aspiradas por 5 min para placas de Petri contendo meio seletivo para B. cereus - ágar MYP (Mannitol yolk polymixin agar; Difco), suplementado com $0,1 \%$ de Sulfato de Polimixina B (Sigma). As coletas foram realizadas através do equipamento Microbiological
Air Sampler (MAS 100; Merck).

A amostragem das superfícies de bancadas e dos equipamentos foi realizada utilizando-se o “método de contato com esponja”, através de esponjas previamente umedecidas com solução de tampão fosfato (Butterfield's phosphate-buffered dilution water, $\mathrm{pH} 7,2)$ suplementado com polisorbato e tiossulfato de sódio a 0,5\%. A área amostrada por bancada foi de $60 \times 70 \mathrm{~cm}$ e o resultado expresso em $\mathrm{cm}^{2}$. Quanto aos equipamentos, as amostras foram coletadas das áreas que têm contato com os alimentos, sendo o resultado expresso como ausência ou presença de $\boldsymbol{B}$. cereus. Após a amostragem, as esponjas foram “massageadas” por 15s com diluente (solução tampão fosfato, pH 7,2). Em seguida, foram realizadas inoculações $(0,1 \mathrm{ml})$ de cada uma das amostras, em placas contendo meio seletivo para B. cereus (ágar MYP).

Isolamento, confirmação e identificação de Bacillus cereus

A contagem, o isolamento, a confirmação e a identificação de $\boldsymbol{B}$. cereus foram realizadas conforme metodologia recomendada por RHODEHAMEL \& HARMON (1998). Uma cepa padrão (B. cereus ATCC 11145) foi utilizada como controle. Após as análises para a confirmação, foram realizados testes para a diferenciação de outros membros do grupo do $\boldsymbol{B}$. cereus (Bacillus anthracis, Bacillus thuringiensis e Bacillus mycoides).

As placas contendo ágar MYP, inoculadas com amostras ambientais, foram incubadas a $30^{\circ} \mathrm{C} / 24 \mathrm{~h}$. Posteriormente, de cada placa contendo colônias típicas do microrganismo (colônias não fermentadoras de manitol e produtoras de lecitinase), foram isoladas entre três e cinco colônias típicas. Esses isolados suspeitos para $\boldsymbol{B}$. cereus foram mantidos em ágar nutriente (Nutrient agar; Merck) a $4^{\circ} \mathrm{C}$. Em seguida, eles foram confirmados e identificados através da coloração de Gram, da reação da catalase, da mentação anaeróbia da glicose, da redução de nitrato, do teste VP (Voges-Proskauer) modificado, da decomposição da tirosina, da resistência a lisozima, do teste de motilidade, do crescimento rizóide e da atividade hemolítica. A detecção de cristais de toxinas para a diferenciação da espécie $\boldsymbol{B}$. thuringiensis foi realizada segundo metodologia descrita por SHARIF \& ALAEDDINOGLU (1988).

Avaliação da produção de enterotoxinas através de ELISA ePCR

Culturas

Setenta isolados, provenientes de amostras de ar e de superfícies, com perfil clássico de B. cereus 
nos testes bioquímicos de confirmação e de identificação da espécie, foram cultivados em caldo BHI (Brain heart infusion broth; Difco), suplementado com $0,1 \%$ de glicose, e incubados a $30^{\circ} \mathrm{C} / 18 \mathrm{~h}$ para a avaliação da produção de enterotoxinas. Uma cepa padrão (B. cereus ATCC 14579) foi utilizada como controle.

\section{ELISA e PCR}

A produção da enteroxina não-hemolítica foi avaliada através de ELISA, utilizando-se o Bacillus Diarrhoeal Enterotoxin Visual Immunoassay (kit BDE, vs MS2207 05/01; Tecra, Roseville New South Wales, Austrália). Este ensaio detecta a proteína de 45kDa da NHE, codificada pelo gene nheA, e foi realizado conforme as instruções do fabricante.

A presença de genes que codificam os complexos HBL e NHE foi verificada através da técnica da PCR. Os iniciadores (primers) utilizados para a amplificação dos genes associados à produção das enterotoxinas estão listados na tabela 1. A extração e as condições de amplificação do DNA foram realizadas conforme metodologia adotada por HANSEN \& HENDRIKSEN (2001). Para a extração, uma alçada da massa bacteriana crescida em meio sólido foi transferida para um tubo Eppendorf, onde foram adicionados $200 \mu \mathrm{l}$ de água Milli-Q esterilizada. As células bacterianas foram lisadas através da incubação a $102^{\circ} \mathrm{C}$ por $10 \mathrm{~min}$ e os fragmentos foram removidos por centrifugação a 13.000 x g por 3min. O sobrenadante com o DNA bacteriano foi estocado a $4^{\circ} \mathrm{C}$. A amplificação do DNA foi realizada em Termociclador Mastercycler ${ }^{\circledR}$ gradient (Eppendorf), utilizando-se 30 ciclos de desnaturação a $94^{\circ} \mathrm{C}$ por 15 s, anelamento a $55^{\circ} \mathrm{C}$ por 45 s e extensão a $72^{\circ} \mathrm{C}$ por $2 \mathrm{~min}$. Para cada reação de amplificação, foi preparado um volume total de reação de $30 \mu$, contendo
$1 \mu \mathrm{l}$ da enzima Taq DNA polimerase $\left(1 \mathrm{U}^{\mathrm{l}} \mathrm{l}^{-1}\right) ; 3 \mu \mathrm{l}$ de tampão 10x (200mM Tris-HCl-pH 8,0; 500mM de KCl); $1 \mu \mathrm{l}$ de $\mathrm{MgCl}_{2} ; 0,24 \mu \mathrm{l}$ de dNTPs $25 \mathrm{mM} ; 1 \mu \mathrm{l}$ de cada um dos primers; $7 \mu \mathrm{l}$ do DNA extraído e água Milli-Q esterilizada (qsp 30 $\mu \mathrm{l}$ ). Os produtos da PCR foram visualizados em gel de agarose a $2 \%$, através do sistema de eletroforese horizontal submersa (SAMBROOK et al., 1989). A identificação dos produtos amplificados foi efetuada com o auxílio de um marcador de peso molecular (100pb ladder, Biotools), utilizado em todos os géis de agarose analisados.

\section{RESULTADOS E DISCUSSÃO}

Trezentas e trinta e uma colônias suspeitas, isoladas de amostras de ar ambiente e de superfícies, foram submetidas aos testes microbiológicos e bioquímicos de confirmação e identificação. Deste total, $76,1 \%$ foram identificados como $\boldsymbol{B}$. cereus. Outras duas espécies do grupo do $\boldsymbol{B}$. cereus também foram identificadas: B. mycoides (4,5\%) e B. thuringiensis (3,6\%). Tal como B. cereus, essas espécies foram identificadas em amostras de ar ambiente e de superfícies.

Os resultados obtidos através das análises microbiológicas revelaram a presença de $\boldsymbol{B}$. cereus no ar ambiente de $84,4 \%$ do total das amostras coletadas em ambos os restaurantes (Tabelas 2 e 3). No R1, as contagens de $\boldsymbol{B}$. cereus variaram entre 2,0 e 38,4UFC $\mathrm{m}^{-3}$ de ar (Tabela 2). Nesse estabelecimento, as áreas onde foram observados os maiores pontos de contaminação foram as áreas de cocção $\left(38,4 \mathrm{UFC} \mathrm{m}^{-3}\right)$, distribuição (28,0UFC m³ ${ }^{-3}$ e self-service (27,6UFC m³ ${ }^{-3}$. No R2, as contagens de $\boldsymbol{B}$. cereus em amostras de ar ambiente variaram entre 2,0 e 20,0UFC $\mathrm{m}^{-3}$ de ar (Tabela 3), sendo observado o maior valor na área recepção de gêneros (20,0UFC m³).

Tabela 1 - Genes e primers utilizados na PCR para a caracterização enterotoxigênica de isolados de Bacillus cereus provenientes de amostras ambientais.

\begin{tabular}{|c|c|c|c|c|}
\hline Gene & primer & Seqüência (5'-3') & Posição do primer & Referência \\
\hline \multirow[t]{2}{*}{ hblA } & HBLA1 & GTGCAGATGTTGATGCCGAT & $671-690 \rightarrow$ & \multirow{2}{*}{$\begin{array}{l}\text { HEINRICHS et al. (1993); HANSEN \& } \\
\text { HENDRIKSEN (2001) }\end{array}$} \\
\hline & HBLA2 & ATGCCACTGCGTGGACATAT & $990-971 \leftarrow$ & \\
\hline \multirow[t]{2}{*}{$h b l D$} & L1A & AATCAAGAGCTGTCACGAAT & $2854-2873 \rightarrow$ & \multirow{2}{*}{$\begin{array}{l}\text { RYAN et al. (1997); HANSEN } \\
\text { \& HENDRIKSEN (2001) }\end{array}$} \\
\hline & L1B & CACCAATTGACCATGCTAAT & $3283-3264 \leftarrow$ & \\
\hline \multirow[t]{2}{*}{ hblC } & $\mathrm{L} 2 \mathrm{~A}$ & AATGGTCATCGGAACTCTAT & $1448-1467 \rightarrow$ & \multirow{2}{*}{$\begin{array}{l}\text { RYAN et al. (1997); HANSEN } \\
\text { \& HENDRIKSEN (2001) }\end{array}$} \\
\hline & L2B & CTCGCTGTTCTGCTGTTAAT & $2197-2178 \leftarrow$ & \\
\hline \multirow[t]{2}{*}{ nheA } & nheA 344 S & TACGCTAAGGAGGGGCA & $344-360 \rightarrow$ & \multirow{2}{*}{$\begin{array}{l}\text { GRANUM et al. (1999); GHELARDI et } \\
\text { al. (2002) }\end{array}$} \\
\hline & nheA 843 A & GTTTTTATTGCTTCATCGGCT & $843-823 \leftarrow$ & \\
\hline \multirow[t]{2}{*}{ nheB } & nheB $1500 \mathrm{~S}$ & CTATCAGCACTTATGGCAG & $1500-1518 \rightarrow$ & \multirow{2}{*}{$\begin{array}{l}\text { GRANUM et al. (1999); GHELARDI et } \\
\text { al. (2002) }\end{array}$} \\
\hline & nheB 2269 A & ACTCCTAGCGGTGTTCC & $2269-2253 \leftarrow$ & \\
\hline \multirow[t]{2}{*}{ nheC } & nheC $2820 \mathrm{~S}$ & CGGTAGTGATTGCTGGG & $2820-2836 \rightarrow$ & \multirow{2}{*}{$\begin{array}{l}\text { GRANUM et al. (1999); GHELARDI et } \\
\text { al. (2002) }\end{array}$} \\
\hline & nheC 3401 A & CAGCATTCGTACTTGCCAA & $3401-3383 \leftarrow$ & \\
\hline
\end{tabular}


Tabela 2 - Bacillus cereus em amostras ambientais do restaurante institucional 1, segundo o tipo de amostra e local de coleta.

\begin{tabular}{|c|c|c|}
\hline Tipo de amostra e local de coleta & $\begin{array}{l}\text { Número de amostras analisadas }\left(\mathrm{n}^{\circ}\right. \\
\text { positivas) }\end{array}$ & Contagem (UFC)* \\
\hline \multicolumn{3}{|l|}{ Ar ambiente } \\
\hline $\begin{array}{l}\text { Áreas de alimentos não-processados: pré-preparo de } \\
\text { vegetais; pré-preparo de carnes; antecâmara; recepção de } \\
\text { gêneros; almoxarifado. }\end{array}$ & $15(12)$ & $2,0-16,0 / \mathrm{m}^{3}$ \\
\hline $\begin{array}{l}\text { Áreas de alimentos processados: carnes preparadas; } \\
\text { cocção. }\end{array}$ & $6(6)$ & $2,0-38,4 / \mathrm{m}^{3}$ \\
\hline $\begin{array}{l}\text { Áreas de alimentos prontos para o consumo: distribuição; } \\
\text { self-service; distribuição de marmitas; monta-cargas. }\end{array}$ & $12(12)$ & $2,0-28,0 / \mathrm{m}^{3}$ \\
\hline Outros locais: manipulação de talheres. & $03(2)$ & $8,0-24,0 / \mathrm{m}^{3}$ \\
\hline \multicolumn{3}{|l|}{ Superfícies de bancadas } \\
\hline $\begin{array}{l}\text { Áreas de alimentos não-processados: pré preparo de } \\
\text { vegetais; pré-preparo de carnes. }\end{array}$ & $12(6)$ & $0,07-0,72 / \mathrm{cm}^{2}$ \\
\hline $\begin{array}{l}\text { Áreas de alimentos processados: carnes preparadas; } \\
\text { cocção. }\end{array}$ & $12(6)$ & $0,07-2,20 / \mathrm{cm}^{2}$ \\
\hline \multicolumn{3}{|l|}{ Superfícies de equipamentos } \\
\hline $\begin{array}{l}\text { Que contatam alimentos não-processados: } \\
\text { multiprocessador; triturador; descascador de legumes; } \\
\text { cortador de legumes. }\end{array}$ & $9(7)$ & NR \\
\hline Que contatam alimentos processados: fatiadores. & $9(6)$ & NR \\
\hline
\end{tabular}

* Unidade Formadora de Colônia.

NR: não realizada.

Do total de amostras de superfícies de bancadas e de equipamentos analisadas, $44,8 \%$ foram positivas para a presença do microrganismo (Tabelas 2 e 3), conforme resultados obtidos nas análises microbiológicas. As maiores contaminações foram observadas nas bancadas do R1 (área de alimentos

Tabela 3 - Bacillus cereus em amostras ambientais do restaurante institucional 2, segundo o tipo de amostra e local de coleta.

\begin{tabular}{|c|c|c|}
\hline Tipo de de coleta amostra e local & $\begin{array}{l}\text { Número de amostras analisadas ( }{ }^{\circ} \\
\text { positivas) }\end{array}$ & $\begin{array}{l}\text { Contagem } \\
\text { (UFC)* }\end{array}$ \\
\hline \multicolumn{3}{|l|}{ Ar ambiente } \\
\hline $\begin{array}{l}\text { Áreas de alimentos não-processados: pré-preparo de vegetais; pré-preparo de } \\
\text { carnes; antecâmara; câmara de resfriamento de carnes; seleção de cereais; } \\
\text { preparo de sobremesas; preparo de massas; preparo de sucos; preparo de dietas } \\
\text { especiais; recepção de gêneros. }\end{array}$ & $33(25)$ & $2,0-20,0 / \mathrm{m}^{3}$ \\
\hline Áreas de alimentos processados: cocção; dietética. & $6(6)$ & $2,0-6,0 / \mathrm{m}^{3}$ \\
\hline $\begin{array}{l}\text { Áreas de alimentos prontos para o consumo: distribuição; self-service; } \\
\text { distribuição de refeições especiais; carros de distribuição de refeições. }\end{array}$ & $12(10)$ & $2,0-8,0 / \mathrm{m}^{3}$ \\
\hline Outros locais: área de entrada de funcionários. & $3(3)$ & $5,4-8,0 / \mathrm{m}^{3}$ \\
\hline \multicolumn{3}{|l|}{ Superfícies de bancadas } \\
\hline $\begin{array}{l}\text { Áreas de alimentos não-processados: pré-preparo de vegetais; pré-preparo de } \\
\text { carnes }\end{array}$ & $24(8)$ & $0,07-0,56 / \mathrm{cm}^{2}$ \\
\hline Áreas de alimentos processados: carnes preparadas; cocção. & $9(0)$ & $<0,0024 / \mathrm{cm}^{2}$ \\
\hline \multicolumn{3}{|l|}{ Superfícies de equipamentos } \\
\hline $\begin{array}{l}\text { Que contatam alimentos não-processados: multiprocessador; descascador de } \\
\text { legumes; cortador de legumes. }\end{array}$ & $15(6)$ & NR \\
\hline Que contatam alimentos processados: fatiadores. & $6(4)$ & NR \\
\hline
\end{tabular}

* Unidade Formadora de Colônia.

NR: não realizada. 
processados - carnes preparadas) com contagens compreendidas entre 0,07 e 2,20UFC cm-2 (Tabela 2).

$\mathrm{Na}$ análise dos resultados obtidos utilizando-se a PCR (Tabela 4 e Figura 1), foi observado que, dos 70 isolados de B. cereus investigados, 14,3\% foram positivos para os três genes que codificam a hemolisina BL (hblA, hblD e hblC); 55,7\% apresentaram um ou dois desses genes e nenhum dos três genes foi detectado em 25,7\% dos isolados. Os três genes que codificam o complexo NHE (nheA, nheB e nheC) foram detectados em $12,8 \%$ dos isolados. Um ou dois desses genes foram detectados em $60,0 \%$ dos isolados e nenhum dos três genes foi observado em $22,8 \%$ dos isolados. Os três genes da HBL e os três genes da NHE foram detectados em três isolados (4,3\%), provenientes de amostras de ar ambiente coletada em área de alimentos não-processados (almoxarifado), de amostras de superfícies de bancada da área de pré-vegetais e de fatiador.

Entre os 70 isolados de $\boldsymbol{B}$. cereus foram identificados 35 perfis toxigênicos distintos. Os 43 isolados provenientes do R1 foram agrupados em 24

Tabela 4 - Perfil toxigênico de Bacillus cereus isolados de amostras ambientais coletadas nos restaurantes institucionais 1 e 2.

\begin{tabular}{|c|c|c|c|c|c|c|c|c|}
\hline \multirow{2}{*}{ Perfil } & \multirow{2}{*}{ Origem $^{a}$} & \multirow{2}{*}{$\begin{array}{l}\text { Número de isolados }\left(\mathrm{n}^{\circ} \text { de }\right. \\
\left.\text { positivos ao teste ELISA }{ }^{\mathrm{b}}\right)\end{array}$} & \multicolumn{3}{|c|}{$\mathrm{HBL}^{\mathrm{c}}$} & \multicolumn{3}{|c|}{$\mathrm{NHE}^{\mathrm{c}}$} \\
\hline & & & $h b l A$ & hblD & hblC & nheA & nheB & nheC \\
\hline $\mathrm{I}$ & $\mathrm{SB}, \mathrm{SE}, \mathrm{A}$, & $3(3)$ & + & + & + & + & + & + \\
\hline II & $\mathrm{SB}, \mathrm{A}$ & $2(2)$ & + & + & + & + & - & + \\
\hline III & SE, SB & $3(3)$ & + & + & + & + & - & - \\
\hline IV & A & $3(2)$ & + & + & + & + & + & - \\
\hline V & A & $1(1)$ & + & + & - & + & + & + \\
\hline VI & A & $3(2)$ & + & + & - & + & - & - \\
\hline VII & A & $2(1)$ & + & + & - & - & + & - \\
\hline VIII & A, SE & $2(1)$ & + & + & - & + & + & - \\
\hline IX & A & $4(0)$ & + & + & - & - & - & - \\
\hline $\mathrm{X}$ & SE & $1(1)$ & - & + & + & - & + & + \\
\hline XI & SB & $1(0)$ & - & + & + & - & - & - \\
\hline XII & $\mathrm{SE}$ & $1(1)$ & + & - & + & - & + & + \\
\hline XIII & SE & $2(0)$ & + & - & + & - & - & - \\
\hline XIV & $\mathrm{A}, \mathrm{SB}, \mathrm{SE}$ & $5(1)$ & - & + & - & - & - & - \\
\hline XV & A & $3(3)$ & - & + & + & + & + & + \\
\hline XVI & A & $1(0)$ & - & + & - & + & - & - \\
\hline XVII & A & $1(1)$ & - & + & - & + & + & + \\
\hline XVIII & A & $1(1)$ & - & - & + & + & + & + \\
\hline XIX & A & $3(2)$ & - & - & + & + & + & - \\
\hline $\mathrm{XX}$ & A & $6(5)$ & - & - & - & + & + & - \\
\hline XXI & SB & $2(2)$ & - & - & - & + & + & + \\
\hline XXII & SE & $2(0)$ & - & - & - & - & + & + \\
\hline XXIII & A, SB & $3(0)$ & - & - & - & - & - & - \\
\hline XXIV & A, SB & $3(3)$ & - & - & - & + & - & + \\
\hline XXV & A & $1(0)$ & + & + & + & - & - & - \\
\hline XXVI & SE & $1(1)$ & + & + & + & - & - & + \\
\hline XXVII & A & $2(2)$ & + & + & - & - & + & + \\
\hline XXVIII & A & $1(1)$ & - & + & - & + & + & - \\
\hline XXIX & A & $1(1)$ & - & + & + & + & - & + \\
\hline XXX & A & $1(1)$ & - & + & + & - & + & - \\
\hline XXXI & A & $1(0)$ & - & - & - & + & - & - \\
\hline XXXII & SE & $1(1)$ & + & - & + & + & + & + \\
\hline XXXIII & SE & $1(0)$ & - & - & - & - & + & - \\
\hline XXXIV & SB & $1(0)$ & - & + & + & - & - & + \\
\hline XXXV & SB & $1(1)$ & - & + & + & + & - & - \\
\hline
\end{tabular}

${ }^{a}$ SB: superfície de bancada; SE: superfície de equipamento; A: ar ambiente

${ }^{\mathrm{b}}$ kit BDE (Tecra). Os resultados foram obtidos de acordo com as instruções do fabricante.

${ }^{\mathrm{c}}+$ : foi observado produto da PCR com peso esperado;

-: não foi observado produto do PCR com peso esperado.

Ciência Rural, v.38, n.2, mar-abr, 2008. 


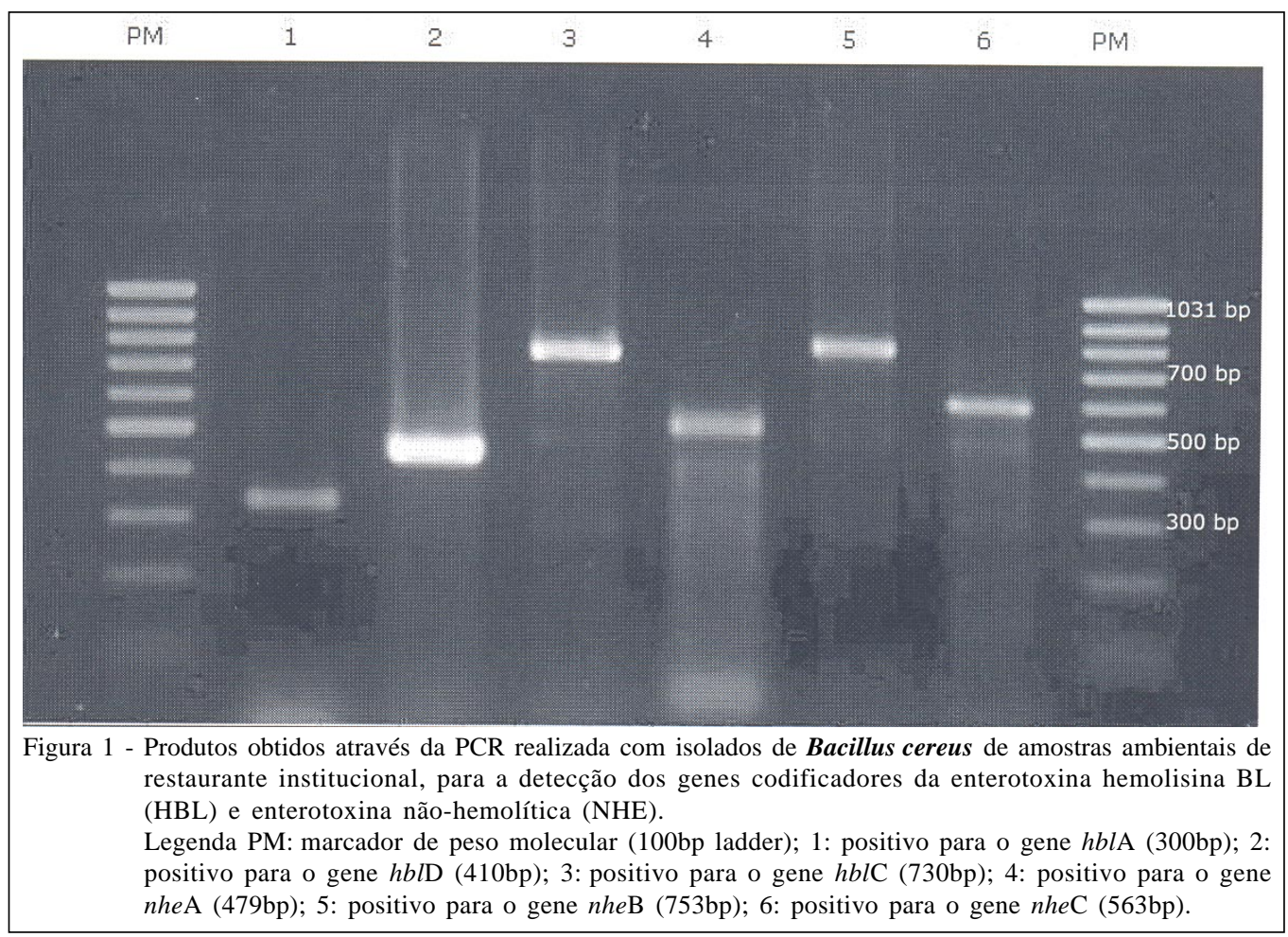

perfis, enquanto os 27 isolados do R2 foram agrupados em 22 perfis. Estudos recentes (HANSEN \& HENDRIKSEN, 2001; GHELARDI et al., 2002; PHELPS \& MCKILIP, 2002), em que foram utilizados métodos baseados na PCR, atestam a heterogeneidade em $\boldsymbol{B}$. cereus quanto à presença de fatores de virulência.

O teste com o kit BDE (Tecra), que detecta a proteína codificada pelo gene nheA do complexo NHE (Lund; Granum, 1996), revelou que 61,4\% dos 70 isolados de $\boldsymbol{B}$. cereus testados produzem essa toxina. Estes resultados confirmam a eficiência do teste, já relatada por outros pesquisadores (LUND \& GRANUM, 1996; LUND \& GRANUM, 1997; HANSEN \& HENDRIKSEN, 2001). Entretanto, entre os 70 isolados, oito apresentaram resultados positivos para o teste ELISA, mesmo sendo negativos para a presença do gene nheA utilizando-se a PCR. Cabe ressaltar que o kit, além de detectar proteína de $45 \mathrm{kDa}$, também pode identificar o componente protéico de $105 \mathrm{kDa}$ do complexo NHE, embora com sensibilidade 10 vezes menor (GRANUM, 1997). De fato, o gene nheC, que codifica esse componente, foi detectado em cinco dos oito isolados que apresentaram resultados positivos no imunoensaio. As propriedades do teste BDE e os possíveis diferenças nas seqüências dos genes codificadores das enterotoxinas devem ser consideradas na análise comparativa entre os resultados obtidos com a aplicação do kit e com a pesquisa de genes do complexo NHE pela PCR, como observaram HANSEN \& HENDRIKSEN (2001).

A presença de $\boldsymbol{B}$. cereus potencialmente produtores de enterotoxinas em amostras ambientais coletadas nos serviços de alimentação, observada através da análise dos resultados obtidos com a PCR e o teste ELISA, indica a importância do risco de contaminação de alimentos a partir dessas fontes. A identificação dos principais locais como origens potenciais do microrganismo ou de seus esporos deve ser considerada para evitar ou reduzir a contaminação dos alimentos na linha de processamento, como relatam alguns pesquisadores (GUINEBRETIERE \& NGUYENTHE, 2003). Neste trabalho, ficou evidente a importância do ar ambiente como fonte de B. cereus em estabelecimentos processadores de alimentos.

\section{CONCLUSÃO}

Devido à freqüência com que determinadas situações são observadas em serviços de alimentação, tais como a exposição do alimento ao ar ambiente por tempo prolongado, condições de higiene de bancadas e de equipamentos inadequadas e exposição dos alimentos a temperaturas abusivas, torna-se relevante insistir na necessidade de aprimorar os procedimentos de higienização ambiental, uma vez que seu papel como fonte potencial de patógenos alimentares como $\boldsymbol{B}$. cereus, tem sido evidenciado de forma indubitável. 


\section{AGRADECIMENTOS}

À Fundação de Amparo à Pesquisa do Estado de São Paulo (FAPESP), pelo apoio financeiro. Ao Prof. Dr. Tomomasa Yano do Instituto de Biologia, UNICAMP, pelo auxílio nas análises da PCR.

\section{REFERÊNCIAS}

ANDERSSON, A. et al. What problems does the food industry have the spore-forming pathogens Bacillus cereus and Clostridium perfrigens? International Journal of Food Microbiology, v.28, n.2, p.145-155, 1995.

BEECHER, D.J.; MACMILLAN, J.D. Characterization of the components of hemolysin BL from Bacillus cereus. Infection and Immunity, v.59,n.5, p.1778-1784, 1991.

BEECHER, D.J. et al. Enterotoxic activity of hemolysin BL from Bacillus cereus. Infection and Immunity, v.63, n.11, p.4423-4428, 1995.

EVANCHO et al. Microbiological monitoring of the food processing environment. In: DOWNES, F.P.; ITO, K. Compendium of methods for the microbiological examination of foods. 4.ed. Washington, DC: American Public Health Association, 2001. cap.3, p.25-35.

GHELARDI, E. et al. Identification and characterization of toxigenic B. cereus isolates responsible for two food-poisoning outbreaks. FEMS Microbiology Letters, v.208, n.1, p.129134, 2002.

GRANUM, P.E. Bacillus cereus and its toxins. Journal of Applied Bacteriology, Symposium Supplement, n.76, p.61S66S, 1994

GRANUM, P.E. Bacillus cereus. In: DOYLE, M.P. et al. Food microbiology: fundamentals and frontiers. Washington, DC: ASM, 1997. p.327-336.

GRANUM, P.E. et al. The sequence of the non-haemolytic enterotoxin operon from Bacillus cereus. FEMS Microbiology Letters, v.177, n.2, p.225-229, 1999.

GUINEBRETIERE, M.H.; NGUYEN-THE, C. Sources of Bacillus cereus contamination in a pasteurised zucchini purée processing line, differentiated by two PCR-based methods. FEMS Microbiology Ecology, v.43, n.2, p.207-215, 2003.

HANSEN, B.M.; HENDRIKSEN, N.B. Detection of enterotoxin Bacillu cereus and Bacillus thuringiensis strains by PCR analysis.
Applied and Environmental Microbiology, v.67, n.1, p.185189, 2001.

HEINRICHS, A.H. et al. Molecular cloning and characterization of the hblA gene encoding the B component of hemolysin BL from Bacillus cereus. Journal Bacteriology, v.175, p.67606766, 1993.

KOTIRANTA, A. et al. Epidemiology and pathogenesis of Bacillus cereus infections. Microbes and Infection, v.2, n.2, p.189-198, 2000.

KRAMER, J.M.; GILBERT, R.J. Bacillus cereus and other Bacillus species. In: DOYLE, M.P. Food borne bacteria pathogens. New York: Marcel Dekker, 1989. p.21-69.

LUND, T.; GRANUM, P.E. Characterisation of a nonhaemolytic enterotoxin complex from Bacillus cereus isolated after a food borne outbreak. FEMS Microbiology Letters, v.141, n.2-3, p.151-156, 1996.

LUND, T.; GRANUM, P.E. Comparison of biological effect of the two different enterotoxin complexes isolated from three different strains of Bacillus cereus. Microbiology (Reading, England), v.143, pt.10, p.3329-3336, 1997.

PHELPS, R.J.; MCKILLIP, J.L. Enterotoxin production in natural isolates of Bacillaceae outside the Bacillus cereus group. Applied and Environmental Microbiology, v.68, n.6, p.3147-3151, 2002.

RHODEHAMEL, E.J.; HARMON, S.M. Bacillus cereus. In: FOOD AND DRUG ADMINISTRATION. Bacteriological analytical manual. 8.ed. Arlington: Association of Official Analytical Chemists International, 1998. cap.14, p.14.0114.08 .

RYAN, P.A. et al. Molecular cloning and characterization of the genes encoding the $\mathrm{L}_{1}$ and $\mathrm{L}_{2}$ components of hemolysin $\mathrm{BL}$ from Bacillus cereus. Journal Bacteriology, v.179, n.8, p.2551-2556, 1997.

SAMBROOK, J. et al. Molecular clonning: a laboratory manual. 2.ed. New York: Cold Spring Harbor Laboratory, 1989. 120p.

SHARIF, F.A.; ALAEDDINOGLU, G.A. Rapid and simple method for staining of the crystal protein of Bacillus thuringiensis. Journal of Industrial Microbiology, v.3, p.227-229, 1988. 